\title{
PESQUISA TEXTURAL DE MINÉRIO HEMATÍTICO DA JAZIDA DE ÁGUAS CLARAS (MG) PELO MÉTODO DE DIFRAÇÃO DE NÊUTRONS
}

\author{
CLAUDE ESLING*, HORST QUADE**, FRANCIS WAGNER* e ROLAND WALDE**
}

\begin{abstract}
Natural haematite samples are always polycrystalline. In the samples the orientation of the single haematite crystallites, that means the "texture", is more or less pronounced. Beside the universal stage method for texture measurements only for transparent minerals, nowadays the X-ray and neutrons diffractions, is more and more used. With this method it is possible to measure not only transparent minerals but also opaque ones, and the measurements are more rapid and more exact because computer-controlled.

Such texture analysis of banded haematite iron ore types from the Águas Claras Mine near Belo Horizonte/Minas Gerais by X-ray diffraction and neutron diffraction show a strong orientation of the (0001)-basal planes of the haematite crystallites parallel to the principal plane of schistosity (axial plane cleavage $s_{2}$ ). This is an effect of twin-gliding parallel to the (1011) - planes during the main deformation act. From this it may be concluded that the process of secondary iron enrichment giving rise to the formation of rich ore types in the Águas Claras Mine has taken place not later than this deformation.
\end{abstract}

\section{INTRODUÇÃO}

A jazida de minério de ferro de Águas Claras, arredores de Belo Horizonte, Minas Gerais, Brasil, foi a primeira à qual se aplicou um projeto de investigação geológica visando a estabelecer as possiveis interdependências entre a deformação tectônica e o enriquecimento em ferro do minério de alto teor. Este projeto é parte de um programa de cooperação mútua entre geólogos brasileros e alemães (Guba et al., 1980), que já há alguns anos vem sendo patrocinado pelo convênio especial entre o CNPq e o Centro de Pesquisas Nucleares de Juelich (KFA).

Paralelamente à caracterização de estruturas. mesoscópicas e macroscópicas, desenvolveu-se o estudo detalhado das tramas de minério de ferro e de rochas a ele adjacentes, com a finalidade de se averiguar a influência da deformação durante a cristalização e orientação dos minerais. É neste caso, então, particularmente importante obterem-se informações sobre o grau de ordenação dos cristais no arranjo das texturas, bem como o posicionamento espacial dos diversos tipos de tramas para que se possam caracterizar os elementos estruturais.

No estudo de tramas de rochas, pode-se lançar mão dos seguintes métodos: 1 - determinação dos eixos cristalográficos dos cristais do agregado, com o auxílio da platina universal; 2 - métodos da reflexão ou difração de raios $\mathrm{X}$; e 3 - métodos da difração de raios de nêutrons.

A partir de todos os três métodos conseguem-se obter diagramas de textura que dão os contornos de igual densidade em projeção estereográfica. No método da platina universal, os contornos do diagrama correspondem a linhas de igual orientação de eixos cristalinos ao passo que, nos diagramas resultantes dos métodos de raios $\mathrm{X}$ e de nêutrons, são dados por linhas de igual freqüência de impulsos. Sabendo-se que nestes últimos métodos a frequêencia de impulsos é proporcional ao número de faces cristalinas que se dispõe espacialmente de modo a causar reflexão ou difração, propiciam seus respectivos diagramas a obtenção indireta da posição espacial de tais faces, a saber, a posição da normal às mesmas. Escolhendo, por exemplo, a face cristalina (0001) como face de reflexão, obter-se-á um diagrama de distribuição da orientação do eixo cristalográfico $c$, uma vez que este é normal à referida face.

A análise de texturas por meio da difratometria de raios X já foi há muito introduzida na Metalurgia (Wassermann, 1939). No âmbito da Geologia, esta metodologia foi aplicada pela primeira vez no estudo de minérios hematíticos por Neff e Paulitsch (1960). Von. Gehlen (1960) realizou um apanhado sobre os métodos ópticos e roentgenográficos de análise de texturas. Nos anos 60 , seguiu-se um grande número de estudos de tramas de quartzitos e rochas carbonáticas - a compilação dos mesmos é devida a Turner e Weiss (1963) e Carter e Raleigh (1969), o mesmo ocorrendo, nos anos 70, para agregados de pirrotita (Clark e Kelly, 1973; e Atkinson, 1975) e calcopirita (Kelly e Clark, 1975; e Roscoe, 1975). Eichler (1968) realizou em primeira mão uma tentativa de estabelecimento de critérios texturais na verificação da gênese de minérios hematíticos brasileiros. Para tanto, ele utilizou amostras orientadas nas quais estabeleceu a distribuição das orientaç̃̃es dos eixos de hematita. Investigações sobre o comportamento dos cristais de hematita em agregados naturais, durante uma deformação, foram conduzidas por Hennig-Michaeli (1976),

* Laboratoire de Métallurgie Structurale, Université de Metz, lle du Saulcy, F-57.000 Metz, França

** Geologisches Institut, Geologie aussereuropaeischer Laender, Technische Universitaet Clausthal, Leibnizstrasse 10 , D-3392

Clausthal-Zellerfeld, República Federal da Alemanha 
as quais levaram à conclusão da existência de uma orientação preferencial dos eixos cristalinos segundo a direção da maior tensão.

Todos esses trabalhos contribuíram enormemente para a aplicação no âmbito da Geologia da difratometria de raios $\mathrm{X}$. Na análise estrutural o emprego desse método inclui os seguintes procedimentos:

- Análise do arranjo de contornos dos diagramas estereográficos entendidos como caracterizadores de uma deteminada trama.

- Determinação do grau de ordenação da trama com o auxílio da densidade polar.

- Estabelecimento da orientação dos máximos dos diagramas.

- Comparação entre as orientações dos máximos e dos elementos estruturais mesoscópicos.

- Verificação de parâmetros da deformação, da cristalização (recristalização, quando ocorre) e da orientação dos grãos.

A seguir serão apresentados os métodos difratométricos roentgenográfico e de nêutrons, bem como alguns resultados de suas aplicaçōes na análise estrutural de minério de ferro da jazida de Águas Claras. As amostras utilizadas na oportunidade foram coletadas por Hackspacher.

\section{FUNDAMENTOS TEÓRICOS DA ANÁLISE DE TEXTURAS}

DEFINIÇÃO DA FUNÇÃO DE DISTRIBUIÇÃO DE ORIENTAÇOEES (ODF) A cada amostra a ser estudada é associado um primeiro sistema de coordenadores $X Y Z$ e, a cada grão um segundo sistema, assinalado por $A B C$. A escolha dos eixos de tais sistemas é arbitrária, podendo-se, porém, por motivos práticos, lançar mão de elementos da trama, como, por exemplo, segundo Ramsay (1967), fazer-se $X$ paralelo à lineação dominante e $Z$ normal à superfície da foliação. Deve-se notar, entretanto, que nos trabalhos de Wenk e Bunge (1977), como também de Wenk et al. (1980), esses sistemas de coordenadas foram empregados em outro sentido.

Para a rede cristalina trigonal, o sistema de coordenadas é de tal maneira escolhido que $C$ passa a corresponder ao eixo trigonal $c$ e $B$ ao eixo digonal (12i10). A orientação de um cristal do agregado $g=\left(\varphi_{1}, \Phi\right.$, $\varphi_{2}$ ) é realizada por um conjunto de rotações, o qual transporta $X Y Z$ para a posição antes ocupada por $A B C$ (Fig. 1a).

Primeiramente, é feita uma rotação $\varphi_{2}$ em torno de $C$; a seguir , uma segunda rotação $\Phi$ em torno de $A$; e, finalmente, uma rotação $\varphi_{2}$ em torno do eixo $C$, agora deslocado de sua posição original. Assim procedendo, conclui-se que $\varphi_{2}$ é um ângulo azimutal, o qual corresponde ao azimute do eixo $c$ no diagrama (Fig. $1 b$ ). $\varphi_{1}$ é um ângulo de rotação que fornece, exatamente, o azimute da amostra enquanto $\Phi$ é o ângulo formado pela direção do eixo cristalográfico $c$ e pela direção do eixo $Z$ da amostra.

Torna-se possivel, então, fazer uma descrição do agregado policristalino pela função de trama ou função da distribuição de orientação (ODF = orientation distribution function). Esta função de distribuição fornece

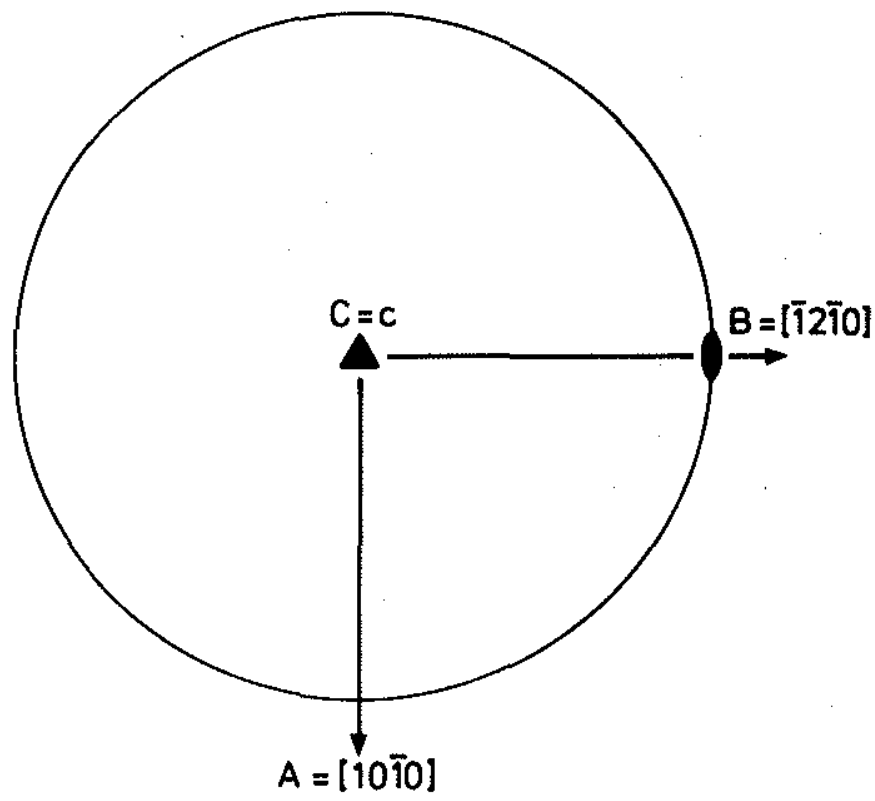

Figura $1 a$ - Definição do sistema $A B C$ de coordenadas cristalográficas da hematita

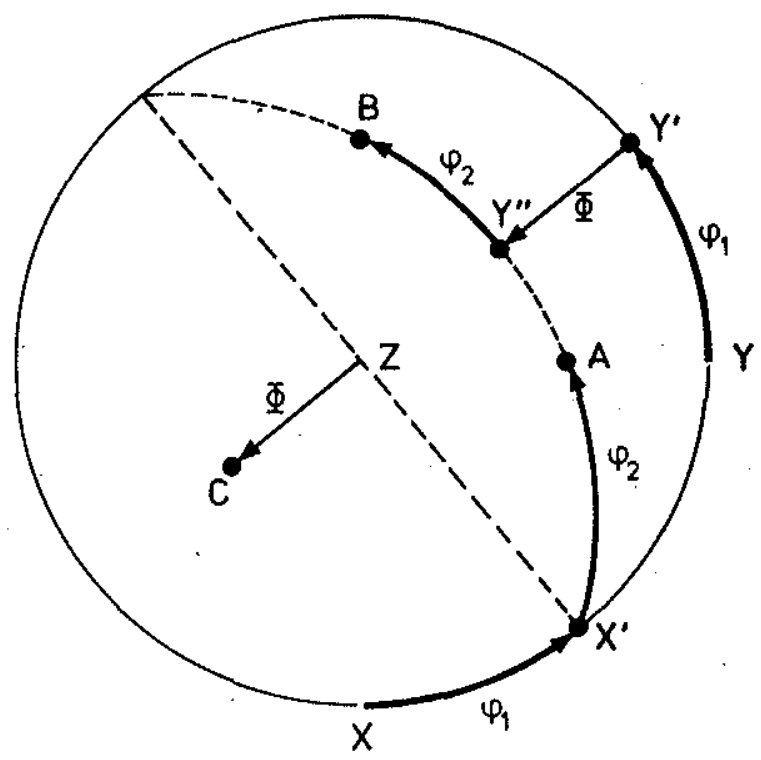

Figura $1 b$ - Definição dos ângulos de Euler $\varphi_{1}, \varphi_{2}$ e $\Phi$, responsáveis pela transformação das coordenadas $X Y Z$ (das amostras) em coordenadas $A B C$ (dos cristais)

a parcela do volume de grãos do agregado, cuja orientação esteja entre $g$ e $g+d g$ (Bunge, 1969):

$$
\frac{d V}{V_{s}}=f(g) \cdot d g
$$

em que $V_{s}$ é o volume total da amostra e $d g=$ $\operatorname{sen} \boldsymbol{\phi}$.d $\varphi_{1}$.d $\varphi_{2}$ é o elemento de integração (volume elementar) no âmbito do ângulo de Euler. 
DEFINIÇÃO DA FIGURA POLAR $\mathrm{P}_{\mathrm{h}}$ (D) OU DIAGRAMA DE TEXTURA A orientação da normal $h_{i}$ a um dado plano cristalográfico, em relação ao sistema de coordenadas de amostra, é determinada por $d=$ $(\Phi, \beta)$, em que $\Phi$ corresponde a seu ângulo de deslocamento em relação à normal da amostra $\mathrm{e} \beta$, ao ângulo azimutal. A figura polar $P_{h_{i}}(\Phi, \beta)$ fornece a intensidade da distribuição de $h_{i}$, polo da direção da amostra $d=$ $(\Phi, \beta)$.

A figura polar ou diagrama de textura contém, naturalmente, menor número de informaçős que uma ODF completa uma vez que ela expressa uma função de apenas duas variáveis angulares $\Phi$ e $\beta$, e não três ângulos de Euler. Ou seja, a figura polar representa uma integração sobre a ODF completa. Por exemplo, de acordo com a precedente escolha de eixos coordenados, o diagrama polar do eixo $c$ representa a integração da ODF ao longo do ângulo $\varphi_{2}$. Em outras palavras, representa a projeção da ODF sobre $\varphi_{2}$.

Embora seja necessário um maior número de diagramas de textura para se poder calcular uma ODF completa, uma atenta interpretação de apenas um ou dois diagramas do gênero permite que se tirem conclusōes de caráter qualitativo a semiquantitativo.

TÉCNICA DE MEDIDAS As figuras polares são, normalmente, medidas com o auxilio de um goniômetro de textura, o qual produz uma rotação da normal à amostra segundo $\Phi$ e $\beta$, dentro dos limites $0 \leqslant ! \leqslant \pi / 2$ e $0 \leqslant \beta \leqslant 2 \pi$, respectivamente. O movimento da amostra (isto é, as variações $\operatorname{de} \Phi \mathrm{e} \beta$ ) pode ser efetuado passo a passo ou continuamente. A Fig. 2 mostra um goniômetro do gênero ajustado na posição de tomada de medidas por reflexão. A inclinação no goniômetro é determinada pelo ângulo $\Phi$ ao passo que a rotação azimutal da amostra em torno de sua normal é dada pelo angulo $\beta$. Este é o denominado método de Schulz. (1949), o qual pode ser utilizado para medidas com raios refletidos e refratados (Decker $e t$ al., 1948). A Fig. 3 mostra uma fotografia de um goniômetro que foi desenvolvido para a difratometria de nêutrons aplicada à análise de tramas e que se encontra acoplado ao reator EL 3, Saclay (França).

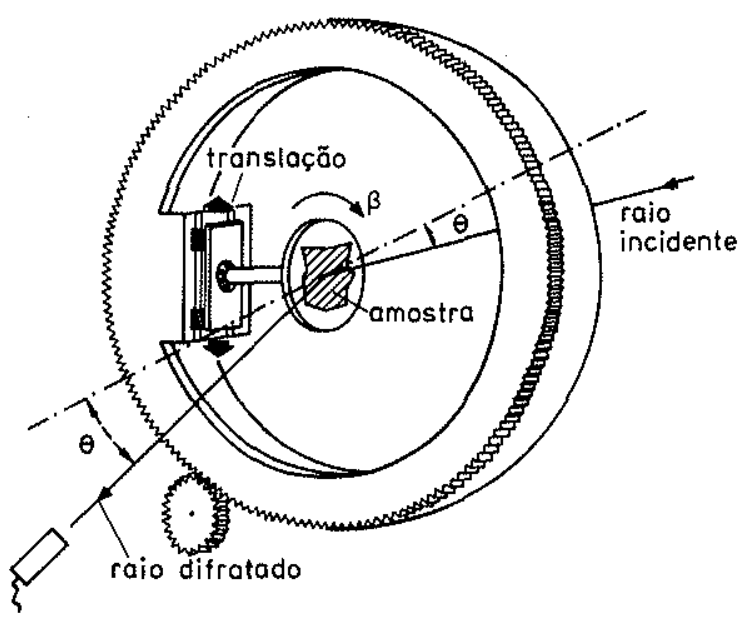

Figura 2 - Montagem da amostra no goniômetro de textura, segundo o método de Schulz

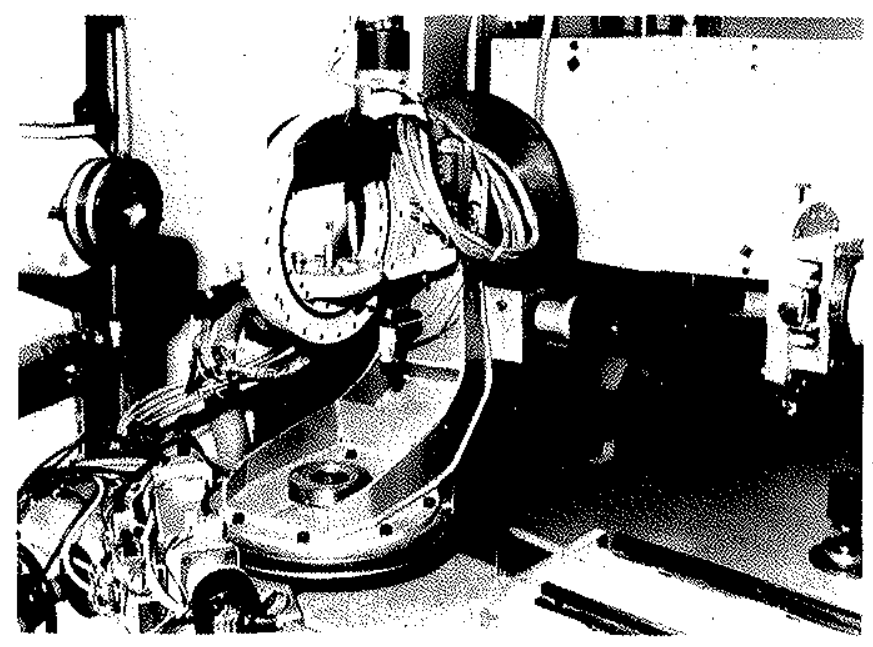

Figura 3 - Goniômetro de textura utilizado no reator de Saclay, França, para tomada de medidas pela difratometria de nêutrons

Para cada posição da amostra são medidas as intensidades de difração dos nêutrons ou dos raios X. Para que a densidade de pólos (figura polar normalizada) e a ODF tenham caráter estatisticamente representativo, é necessário que um grande número de cristais do agregado difratem os raios incidentes.

A execução de medidas de toda a figura polar (isto é, todos os valores de $\Phi \cdot \mathrm{e} \beta$ ) se faz necessária para o cálculo do diagrama de textura ou quando o fator normativo $N_{h_{i}}$ deva ser determinado por:

$$
N_{h_{i}}=\int_{\Phi=0}^{\Phi=\pi / 2} \int_{\beta=0}^{\beta=2} P_{h_{i}}(\Phi, \beta) \operatorname{sen} \Phi \cdot \mathrm{d} \Phi \cdot \mathrm{d} \beta
$$

Para se obter uma figura polar completa pela utilização dos raios $\mathrm{X}$, presume-se que se possa dispor de uma amostra bastante delgada $(0,1 \mathrm{~mm}-0,01 \mathrm{~mm}$ de espessura), pois na confecção da figura polar parte dos dados é obtida por reflexão e parte por refração.

Uma possibilidade de se contornar o problema da confecção de lâminas delgadas consiste na obtenção de três lâminas normais entre si e utilizá-las no método de reflexão. Os dados obtidos a partir de cada uma das três lâminas seriam então posteriormente combinados, obtendo-se assim a figura polar correspondente.

$O$ emprego da difratometria de nêutrons, caso seja possível, permite obter-se uma completa figura polar por um caminho sensivelmente mais simples. $O$ princípio da difratometria de nêutrons é análogo ao da difratometria dos raios $\mathrm{X}$, embora a difração dos raios de nêutrons se dê às expensas da interação dos nêutrons com o núcleo dos átomos da amostra. O magnetismo de certos minerais, no caso de hematita, provoca o aparecimento de efeitos adicionais que se refletem nos diagramas. Devido à pequena absorção dos nêutrons, podem ser utilizados no processo corpos de prova relativamente grandes o que permite a obtenção de figuras polares completas, para amostras de granulação grosseira, que constituem a regra em Geologia. 
$\mathrm{Na}$ maioria dos casos pode-se então expor toda a amostra aos raios de nêutrons sem que nenhuma correção de mudança de volume pela difração seja necessária. Normalmente, é exigida uma correção para a absorção que, entretanto, é de magnitude muito pequena, menor que $2 \%$, quando se trata de amostras de forma cúbica. Constituem exceçðes as amostras com forma esférica ou cilíndrica para as quais não se faz necessária tal correção.

Devido à pequena taxa de absorção, como também à multiplicidade de fatores de dispersão originados por interações atômicas, os quais são bastante pequenos quando comparados aos inerentes ao processo da difração de raios $\mathrm{X}$, torna-se a difração de nêutrons monocromáticos um método muito eficiente para a medida de uma figura polar completa.

\section{DESCRIÇÃO DAS AMOSTRAS E DOS DIAGRA- MAS DE TEXTURA}

ORIENTAÇÃO E PREPARAÇÃO DAS AMOSTRAS $P A R A$ TOMADA DE MEDIDAS Utilizaram-se, para tomada de medidas, amostras do minério compacto, colhidas e orientadas por Hackspacher. A orientação dos planos de xistosidade $s_{2}$ (mais ou menos paralelos aos planos da foliação $s_{1}$ ) foi determinada no local de coleta. Os corpos de prova, confeccionados a partir do corte paralelo a $s_{2}$ nas amostras de mão, foram posteriormente reorientados segundo a direção de mergulho $(X)$, a direção do plano $s_{2}$ e a normal $(Z)$ a esta mesma superfície. Para a difratometria de raios $\mathrm{X}$, foi feita uma placa de dimensóes de $2,5 \times 1,5 \times 0,5 \mathrm{~cm}$, tendo esta uma de suas faces maiores polida, na qual se realizaram as mediçóes. O corpo de prova usado na difratometria de nêutrons constituiu-se de um cubo de $1 \mathrm{~cm}$ de aresta.

AMOSTRA No 1 Na amostra de mão n: 1 (minério xistoso proveniente da região SW da mina de Águas Claras), reconhece-se facilmente uma superfície de xistosidade $\left(s_{2}\right)$, sobre a qual se desenvolvem cristais de especularita. Observa-se ainda, claramente, o desenvolvimento de uma crenulação, segundo a direção SI 5E. Em seção polida paralela $X Y$, observa-se que cristais de especularita tem seus eixos maiores orientados de preferência segundo a direção acima referida. A isto associa-se uma foliação $\left(s_{1}\right)$ oriunda da disposição alternada de lâminas, ora ricas em quartzo, ora ricas em hematita. Os cristais de especularita são idiomórficos, laminares ou alongados, medindo até $0,5 \mathrm{~mm}$ de comprimento, e possuem uma relação comprimento/largura que pode variar entre os limites de 5 a 10:1. Os grãos são livres de inclusőes e envolvem agregados de martita (de ąté $2 \mathrm{~mm}$ de diâmetro), os quais podem localmente orientar-se segundo S15E (Figs. $7 a$ e 7b).

Visto que $95 \%$ dos cristais de especularita, na seção $X Y$, permanecem extintos ao se girar a platina do microscópio, é forçoso concluir-se que um dos eixos cristalográficos dos mesmos esteja coincidindo com o eixo optico do microscópio, ou seja, coincidindo com o eixo $Z$ da amostra.

O diagrama de difração de raios X (Fig. 4) mostra, para a distribuição dos pólos da face romboédrica (1014) da hematita, uma ordenação segundo um meri-

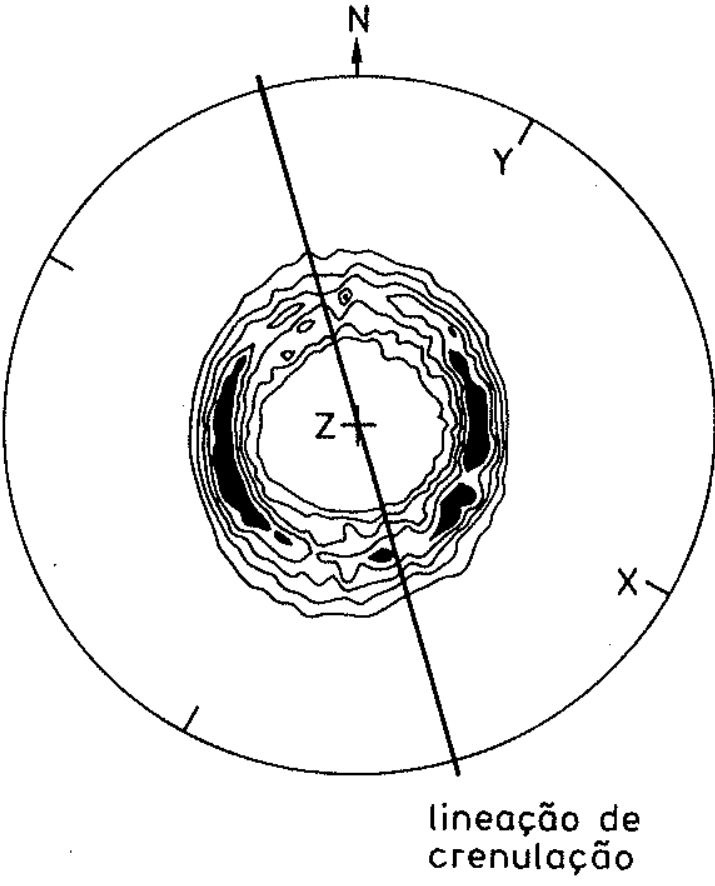

Figura 4 - Amostra n: 1. Distribuição (não-normalizada) da intensidade de reflexóes de raios $X$ na face (1014) da hematita. Esfera superior do estereograma de Wulff. Contornos: 10-20-30-40->50 (frequiência absoluta)

diano em torno de $Z$, fazendo com este um ângulo de cerca de 30 graus e possui dois máximos com $50 \%$ de densidade. Sabendo-se que o pólo da face (1014) faz um ângulo de $21,5^{\circ}$ com o eixo cristalográfico $c$, deduz-se que o eixo $c$ da hematita coincide $\operatorname{com} Z$, ou seja, a face basal dos cristais orientam-se de preferência segundo a superfície $s_{2}$.

AMOSTRA No 2 Esta amostra, proveniente da parte sudoeste da mina, constitui-se de minério xistoso, caracterizado por uma fina laminação: Sobre a superficie $s_{2}$ foi medida uma lineação cuja orientação é S48E. Na seção polida $X Y$, observa-se uma orientação preferencial dos cristais de hematita segundo essa mesma direção. Tais cristais são, em geral, hipidiomórficos, apresentando, em muitos casos, bordas denteadas (Fig. 8). $\mathrm{O}$ tamanho dos mesmos fica em torno de 30 a $50 \mu \mathrm{m}$. Alguns cristais lamelares de especularita orientam-se com seu eixo maior na referida direção S48E. Na superfície $X Y$, observa-se uma orientação mais bem desenvolvida dos cristais de especularita na superfície $s_{2}$.

O diagrama de difração de nêtrons (Fig. 5) mostra a distribuição das orientações do eixo $c$ da hematita da amostra n. 2. Os contornos exibem um máximo em torno de $Z$ e possuem forma elipsoidal. Os eixos maiores das elipses coincidem com uma lineação macroscopicamente reconhecível, ou seja, os eixos da hematita orientam-se de preferência segundo a direção da referida lineação. Pode-se ainda deduzir do diagrama que a face basal (0001) da hematita é de preferência orientada paralelamente à superfície $s_{2}$. 


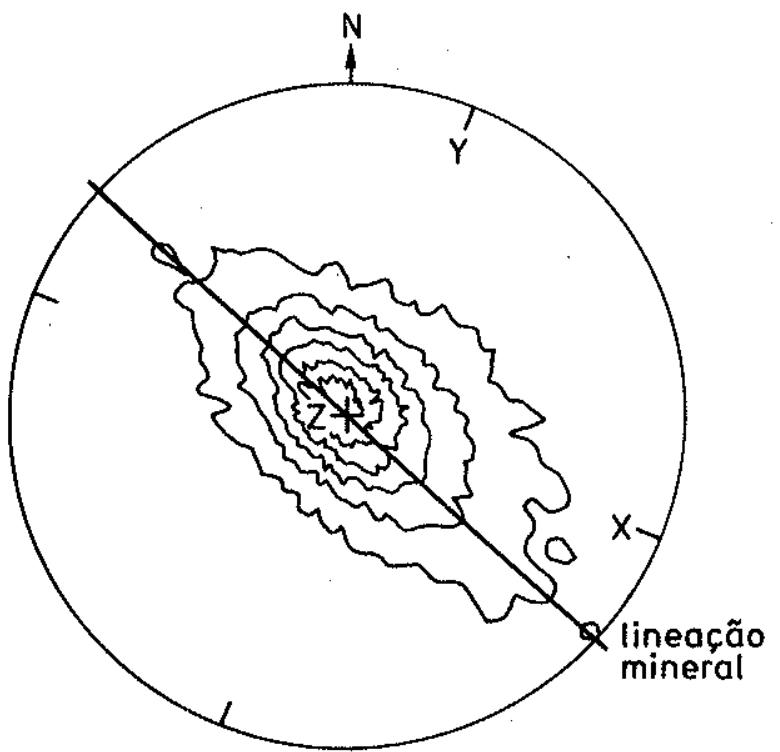

Figura 5 - Amostra n? 2. Distribuição (normalizada) da intensidade de reflexões de raios de nêutrons na face (0001) da hematita. Esfera superior do estereograma de Wulff. Contornos: 1,0-1,5-2,0-2,5-3,0-3,5 (múltiplos dos valores do background)

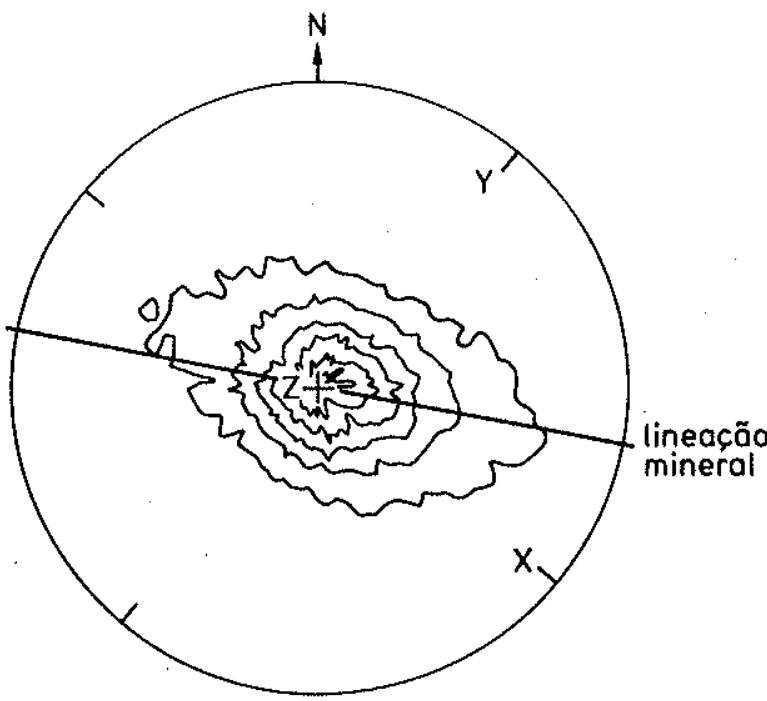

Figura 6 - Amostra n. 3. Distribuição (normalizada) da intensidade de reflexðes de raios de nêutrons na face $(0001)$ da hematita. Esfera superior'do estereograma de Wulff. Contornos: 1,0-1,5-2,0-2,5-3,0-3,5 (múltiplos dos valores do background)

AMOSTRA N: 3 Constitui-se de minério compacto, proveniente também da parte sudoeste da mina. A lineação $(l)$, medida na superfície $s_{2}$, possui, neste caso,"a orientação S80E. Na seção polida $X Y$, nota-se que os cristais hipidiomórficos, alongados, de especularita orientam-se de preferência com seu eixo maior paralelo à direção $\mathrm{S} 80 \mathrm{E}$ anteriormente mencionada (Fig. 9). Esses cristais apresentam-se freqüentemente maclados, possuindo tamanho de cerca de $100 \mu \mathrm{m}$, não mostrando inclusóes. No plano $X Y$, reconhece-se uma tendência da face basal $(0001)$ a se dispor na superfície $s_{2}$, como também a existência de grandes cristais de martita, com cerca de $250 \mu \mathrm{m}$ de tamanho, dispersos na massa de cristais menores de especularita. Os cristais de martita exibem uma ligeira tendência a se orientar segundo S47E.

É bastante expressiva a conformação elipsoidal dos contornos do diagrama de difratometria de nêutrons (Fig. 6) dos eixos $c$ de hematita. O eixo maior dessas elipses concorre com a direção da lineação e o centro das mesmas cai sobre $Z$, ou seja, aqui se concentra o maior número de eixos $c$ de hematita. O diagrama confirma a observação realizada ao microscópio de que a face basal (0001) dos cristais se orienta paralelamente a $s_{2}$.

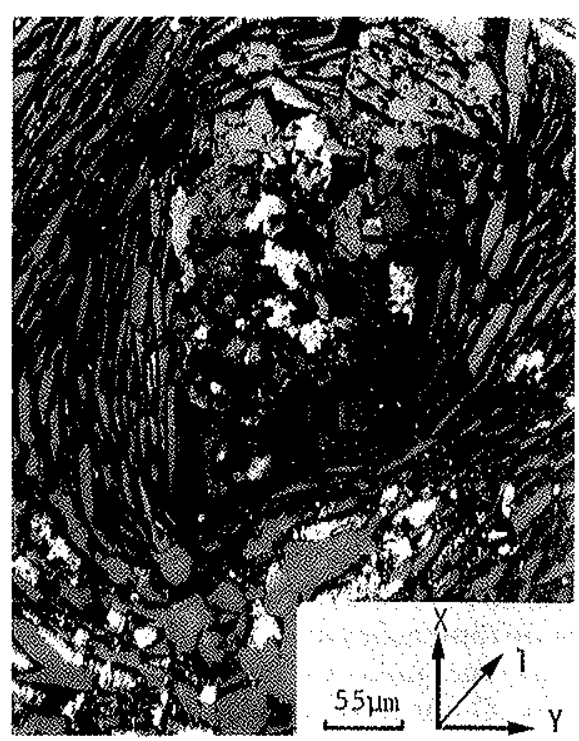

Figura $7 a-$ Fotomicrografia da amostra n: 1 tomada na seção $X Y$, mostrando um relicto de martita circundado por hematita especular (luz refletida, Nicóis cruzados)

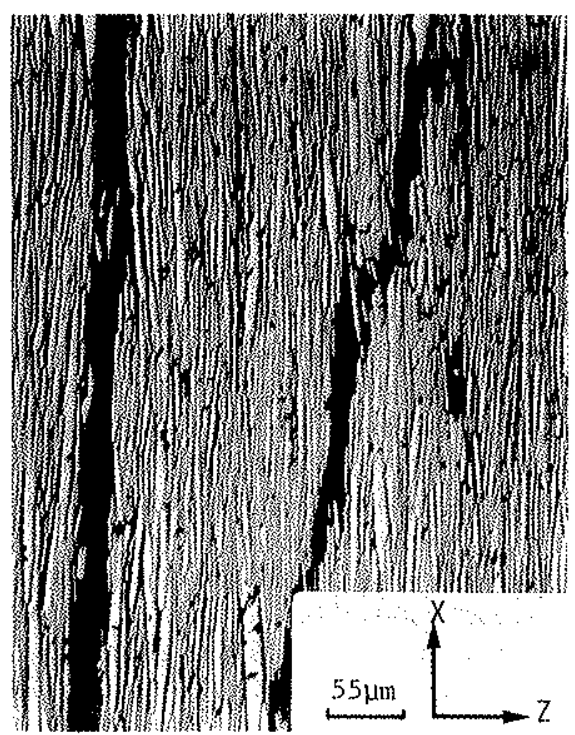

Figura $7 b-$ Fotomicrografia da amostra no 1 tomada na seçåo $X Z$, mostrando cristais de hematita especular fortemente alongados e orientados de preferência segundo $s_{2}(=X Y)$ com seus eixos $c$ segundo $Z$ (luz refletida, Nicóis cruzados) 


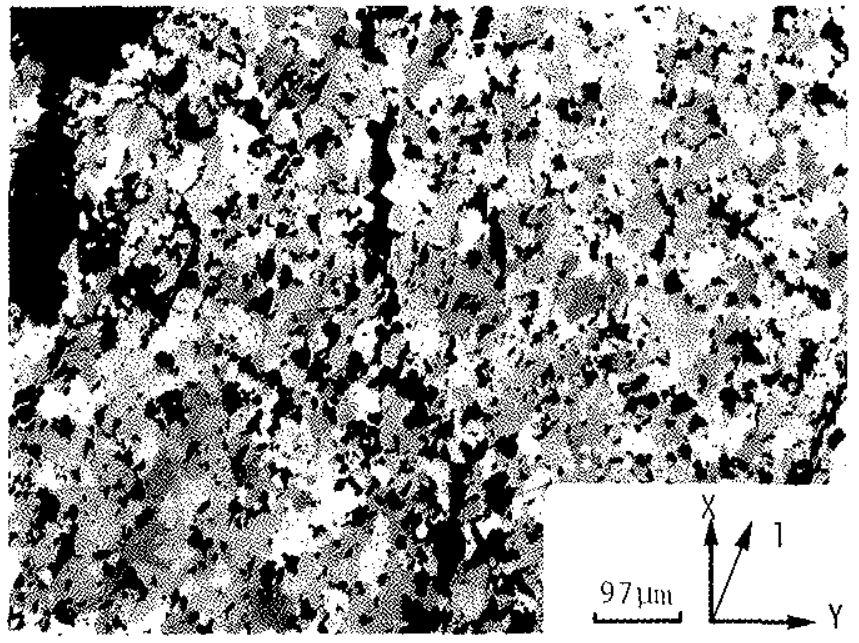

Figura 8 - Fotomicrografia da amostra n: 2 tomada na seção $X Y$, mostrando cristais hipidiomórficos de hematita de bordos denteados (luz refletida, Nicóis cruzados)

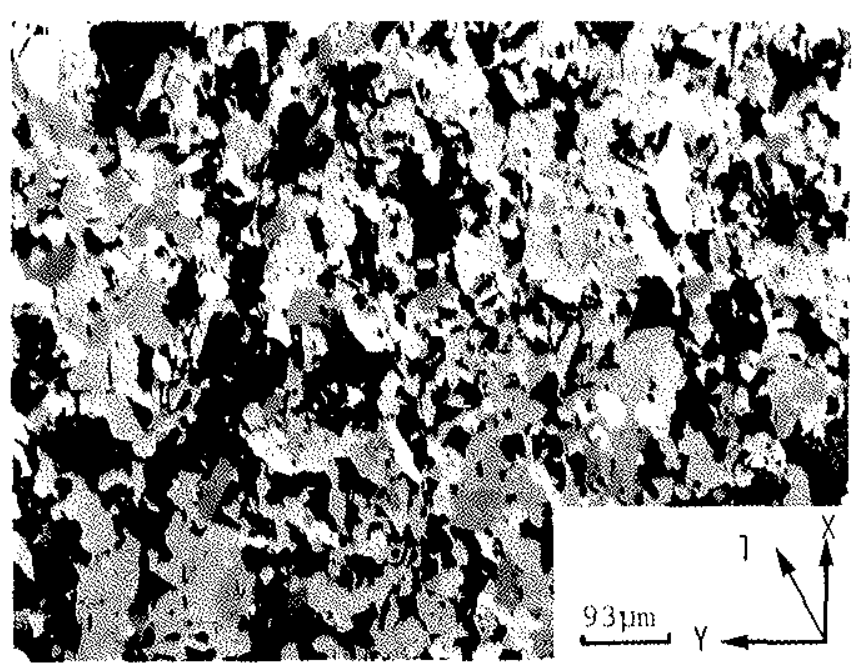

Figura 9 - Fotomicrografia da amostra n: 3 tomada na seçăo $X Y$, mostrando cristais hipidiomórficos e alongados de hematita (luz refletida, Nicois cruzados)

DISCUSSÃO Investigando minérios hematiticos da Suécia, deformados artificial e naturalmente, HenningMichaeli (1976 e 1977) observou que, durante o processo de deformação, ocorre nos cristais do agregado uma forte tendência à maclação segundo (1011) pela qual tem lugar uma translação do eixo $c$ da hematita, partindo da direção de compressão máxima $\sigma_{1}$, no sentido da maior distensão $\sigma_{3}$.

Uma transposição de tais resultados aos diagramas aqui apresentados implica que se faça coincidir a direção de compressão máxima $\sigma_{1}$, com a direção da lineação e, conseqüentemente, com o eixo maior das elipses nos diagramas de textura. Pela mesma razão, $\sigma_{2}$ vem cair sobre a direção do eixo menor das elipses, assentando juntamente com $\sigma_{1}$ sobre a superfície $s_{2}$. A direção de distensão máxima $\sigma_{3}$ orienta-se normalmente à última superfície, ou seja, paralela a $Z$.

Desta maneira, pode-se dizer então que ocorreu no processo de deformação uma compressão, pela qual se desenvolveu a superfície de xistosidade $s_{2}$, com concomitante reorientação de cristais de hematita, maclação.

Acrescente-se a isso o fato de que, na análise de eixos de quartzo efetuada na Quartzito Moeda, rocha adjacente ao jazimento do minério, logrou-se obter uma orientação preferencial doś mesmos, segundo um meridiano em torno de $b\left(=\sigma_{2}\right)$. De acordo com Hofmann (1965), isso implica que um cisalhamento tenha ocorrido em $s_{2}$, afirmativa esta que vem reforçar os resultados aqui apresentados.

As orientaçðes preferenciais tanto da face (0001) dos cristais de hematita na superfície de xistosidade $s_{2}$ como dos eixos maiores desses cristais segundo uma lineação passível de ser reconhecida microscópica e macroscopicamente levam a concluir que o enriquecimento do minério em questão se deu, no mais tardar, durante a deformação.

CONCLUSÃO Dispondo de figuras de minério he matítico da jazida de Águas Claras, arredores de Belo Horizonte, Minas Gerais, Brasil, logrou-se obter algu* mas conclusōes a respeito do processo de deformação do minério. Particularmente, pela orientação preferencial dos eixos $c$ de hematita, em relação a elementos mesoscópicos, pode ser comprovado que o enriquecimento do minério se deu, ao mais tardar, durante a deformação.

Com efeito, as texturas guardam importantes e, prin. cipalmente, singulares informações sobre a história de deformação de uma rocha. Mas a trama observável em determinada amostra é o produto final de todos os eventos deformativos que porventura possam ter ocorrido no decorrer do tempo geológico. Por esta razão, muitas vezes, uma interpretação dificilmente é levada a efeito. Apesar disso, realizaram-se, nos últimos anos, tentativas de aplicação de um modelo de caráter quantitativo a amostras naturais, como é o caso da Teoria de Taylor. Tais estudos deverão, em tempos vindouros, tornar-se sensivelmente mais refinados, levando-se em conta a possibilidade de utilização das funções distributivas tridimensionais.

Parece não haver dúvida de que, em futuro próximo, a análise estrutural quantitativa virá a "inundar" o vasto campo da Geologia, trazendo progressos na interpretação dos mecanismos de deformação e no cálculo dos efeitos da anisotropia.

Agradecimentos . Os autores externam seus agradeci mentos às seguintes instituições: Sociedade Alemã de Pesquisas Científicas (DFG), que possibilitou a realização destes estudos; e CNPq e Centro de Pesquisas Nucleares Juelich (KFA) que, por seu convênio especial, patrocinaram os trabalhos de campo para a investigação geologica de jazidas no Brasil.

Em especial, os autores agradecem ao Sr. Paul Dervin (C.E.N., Saclay) por sua gentileza em ceder a fotografia do goniômetro de texturas bem como pelo auxílio durante as operaçôes com a difratometria de nêutrons. 


\section{BIBLIOGRAFIA}

ATKINSON, W.C. - 1975 - "A preliminary study of the influence of temperature and strain rate on the rheology of a polycrystalline pyrrhotite ore". N. Jb. Miner. Mh.: 483-528.

BUNGE, H.J. - 1969 - "Mathematische Methoden der Texturanalyse". Akademie Verlag, Berlim.

BUNGE, H.J. e WENK, W.R. m 1977 - "Three-dimensional texture analysis of three quartzites (trigonal crystal and triclinic specimen symmetry)"'. Tectonophysics 40: 257-285.

CARTER, N.L. e RALEIGH, B.C. - 1969 - "Principal stress directions from plastic flow in crystals". Geol. Soc. Am. Bull. 80: 1231-1264.

CLARK, B.R. e KELLY, W.C. - 1973 - "Sulfide deformation studies: I. Experimental deformation of pyrrhotite and sphalerite to 2000 bars and $500^{\circ} \mathrm{C}^{\prime \prime}$. Econ. Geol. 68: 332-352.

DECKER, B.F., ASP, E.T. e HARKER, D. - 1948 - "Preferred orientation determination using a Geiger counter X-ray diffraction goniometer", $J$. appl. Phys, 19: 388-392.

EICHLER, J, 1968 - "Geologie und Ent stehung der itabiritischen Reicherze im "Eisernen Viereck" von Minas Gerais/Brasilien". Habil. -m Schrift TU Clausthal: 192 pp. Clausthal-Zellerfeld.

ESLING, C., WAGNER, F., BARO, R. e ENGLANDER, M. - 1978 - “"Textures of Iron Oxides and Topotactical Realationships". Proc. 5th intern. conf. "Texture of Materials": 221-230. Springer-Verlag, Berlim.

GEHLEN, K. von - 1960 - "Die röntgenographische und optische Gefugeanalyse von Erzen, insbesondere mit dem Zăhirohr-Texturgoniometer". Beitr. Miner. Petrogr. 7: 340-388.

GLOCKNER, K.H. e QUADE, H - 1978 - "Der tektonische Baustil des Prăkambriums im südð̋stlichen Eisernen Viereck, Brasilian". 6. Geowiss. Lateinamer. Kolloquium, Stuttgart.

GUBA, I., QUADE, H. e ROSIERE, C.A. - 1980 - "Análise Estrutural dos Jazimentos de Minério de Ferro de Morro Agudo, Água Limpa e Pico de Itabira, Quadrilátero Ferrifero, Minas Gerais". (manuscrito)

HACKSPACHER, P.C. - 1979 - "Strukturelle und texturelle Untersuchungen zur internen Deformation des Eisenreicherzkörpers der Grube "Águas Claras"' bei Belo Horizonte/Minas Gerais, Brasilien". Clausthaler Geol. $A b h$. 34: 164 pp. Clausthal-Zellerfeld.

HENNIG-MICHAELI, C. - 1976 -m "Mikroskopische Gefugeuntersuchungen an experimentell und natürlich verformten Hämatiterzen. Diss. TH Aachen: $225 \mathrm{pp}$.

HENNIG-MICHAELI, C. - 1977 - "Microscopic structure studies of experimentally and naturally deformed hematite ores", Tectonophysics 39: 255-271.
HOFMANN, J. - 1965 - Zur Petrotektonik des Graugneiskomplexes von Freiberg". Freiberger Forschungshefte C 191: 152 pp. VEB Deutscher Verlag fur Grundstoffindustrie, Leipzig.

KELLY, W.C. e CLARK, B.R. - 1975 - " "Sulfide deformation studies: III. Experimental deformation of chalcopyrite to 2000 bars and $500^{\circ} \mathrm{C}^{\prime \prime}$. Econ. Geol. 70: 431-453.

LISTER, G.S. - 1978 - Texture transitions in plastically deformed calcite rocks. Proc. Sth intern. conf, "Texture of Materials": 199-210. SpringerVerlag, Berlim:

MOINEAU, H. e BARO, R. - 1971 - " "Cinétique de réduction en magnétite, de monocristaux d'hématite $\mathrm{Fe}_{2} \mathrm{O}_{\alpha} \alpha$, selon leurs faces naturelles". Bull. Soc. fr. Minéral. Cristallogr. 94: \$44-445.

NEFF, H. e PAULITSCH, P: - 1960- "Rontgenographische Bestimmung der Hämatitregel in natürlichen Gefugen". N. Jb. Miner. Abh. 94: 1401-1410 (Festband RAMDOHR).

POMERENE, J.B. - 1964 - "The geology and ore deposits of the Belo Horizonte, Itabira and Macacos quadrangles, Minas Gerais, Brasil"'. U.S. geol. Surv. prof. Pap. 341D: 84 pp. Washington.

RAMDOHR, P. - 1975 - "Die Erzmineralien und ihre Verwachsungen". 4" ediçao, 1277 pp. Akademie-Verlag, Berlim.

RAMSAY, J.G. - 1967 - "Folding and Fracturing of Rocks". $568 \mathrm{pp.}$ McGraw-Hill Book Co., New York.

ROSCOE, W.E. - 1975 - "Experimental deformation of natural chalcopyrite at temperatures up to $300^{\circ} \mathrm{C}$ over the strain rate range $10^{-2}$ to $10^{-6} \mathrm{sec}$. Econ. Geol. 70: 454-472.

SCHULZ, L.G. - 1949 -. "A direct method of determining preferred orientation of a flat reflection sample using a Geiger counter X-ray spectrometer". J. appl. Phys. 20: 1030-1033.

TURNER, F.J. e WEISS, L.E. - 1963 - "Structural Analysis of Metamorphic Tectonites". McGraw-Hill Book Co., New York.

WASSERMANN, G. - 1939 - "Texturen metallischer Werkstoffe". Springer-Veriag, Berlim.

WENK, W.R., WAGNER, F., ESLING, C. e BUNGE, H.J. - 1980 -.. "Texture Representation of Carbonate Rocks'. Intern. Conf. on the Effect of Deformation on Rocks, Gottingen. Tectonophysics (no prelo).

Recebido em 3 de Abril de 1981. 